Marquette University

e-Publications@Marquette

Biological Sciences Faculty Research and

Publications

Biological Sciences, Department of

7-2019

\title{
Effects of Dry-Season Irrigation on Leaf Physiology and Biomass Allocation in Tropical Lianas and Trees
}

Chris M. Smith-Martin

University of Minnesota

Carolina L. Bastos

São Paulo University

Follow this and additional works at: https://epublications.marquette.edu/bio_fac

Part of the Biology Commons

\section{Recommended Citation}

Smith-Martin, Chris M. and Bastos, Carolina L., "Effects of Dry-Season Irrigation on Leaf Physiology and Biomass Allocation in Tropical Lianas and Trees" (2019). Biological Sciences Faculty Research and Publications. 785.

https://epublications.marquette.edu/bio_fac/785 


\title{
Effects of dry-season irrigation on leaf physiology and biomass allocation in tropical lianas and trees
}

\author{
Chris M. Smith-Martin, ${ }^{1,7}$ Carolina L. Bastos, ${ }^{2}$ Omar R. Lopez, ${ }^{3,4}$ Jennifer S. Powers,,${ }^{1,4,5}$ and \\ Stefan A. Schnitzer ${ }^{4,6}$ \\ ${ }^{1}$ Department of Plant and Microbial Biology, University of Minnesota, St. Paul, Minnesota 55108 USA \\ ${ }^{2}$ Department of Botany, Plant Anatomy Laboratory, São Paulo University (USP), São Paulo, Brazil \\ ${ }^{3}$ Center for Biodiversity and Drug Discovery, Institute for Advanced Research and Technology, City of Knowledge, Clayton, Panama \\ ${ }^{4}$ Smithsonian Tropical Research Institute, Apartado 2072, Balboa, Panama \\ ${ }^{5}$ Department of Ecology, Evolution and Behavior, University of Minnesota, 100 Ecology Building, 1987 Upper Buford Circle, St. Paul, \\ Minnesota 55108 USA \\ ${ }^{6}$ Department of Biology, Marquette University, Milwaukee, Wisconsin 53201 USA
}

Citation: Smith-Martin, C. M., C. L. Bastos, O. R. Lopez, J. S. Powers, and S. A. Schnitzer. 2019. Effects of dry-season irrigation on leaf physiology and biomass allocation in tropical lianas and trees. Ecology 100(11):e02827. 10.1002/ecy.2827

\begin{abstract}
Lianas are more abundant in seasonal forests than in wetter forests and are thought to perform better than trees when light is abundant and water is limited. We tested the hypothesis that lianas perform better than trees during seasonal drought using a common garden experiment with 12 taxonomically diverse species (six liana and six tree species) in 12 replicated plots. We irrigated six of the plots during the dry season for four years, while the remaining six control plots received only ambient rainfall. In year 5 , we measured stem diameters for all individuals and harvested above- and belowground biomass for a subset of individuals to quantify absolute growth and biomass allocation to roots, stems, and leaves, as well as total root length and maximum rooting depth. We also measured rate of photosynthesis, intrinsic water use efficiency (iWUE), pre-dawn and midday water potential, and a set of functional and hydraulic traits. During the peak of the dry season, lianas in control plots had $54 \%$ higher predawn leaf water potentials $\left(\Psi_{\mathrm{PD}}\right)$, and $45 \%$ higher photosynthetic rates than trees in control plots. By contrast, during the peak of the wet season, these physiological differences between lianas and trees become less pronounced and, in some cases, even disappeared. Trees had higher specific leaf area (SLA) than lianas; however, no other functional trait differed between growth forms. Trees responded to the irrigation treatment with 15\% larger diameters and $119 \%$ greater biomass than trees in control plots. Liana growth, however, did not respond to irrigation; liana diameter and biomass were similar in control and irrigation plots, suggesting that lianas were far less limited by soil moisture than were trees. Contrary to previous hypotheses, lianas did not have deeper roots than trees; however, lianas had longer roots per stem diameter than did trees. Our results support the hypothesis that lianas perform better and experience less physiological stress than trees during seasonal drought, suggesting clear differences between growth forms in response to altered rainfall regimes. Ultimately, better dry-season performance may explain why liana abundance peaks in seasonal forests compared to trees, which peak in abundance in less seasonal, wetter forests.
\end{abstract}

Key words: climate change; drought; liana increases; rooting depth; seasonality; trees; tropical forests; whole-plant harvest.

\section{INTRODUCTION}

Understanding the factors that control the abundance and distribution patterns of plant species is a fundamental goal in ecology. One of the main drivers of species distributions in tropical biomes is rainfall gradients, and plant species composition and forest structure shift considerably across broad precipitation gradients (Beard

Manuscript received 30 October 2018; revised 7 June 2019; accepted 17 June 2019. Corresponding Editor: Truman P. Young.

${ }^{7}$ E-mail: chrismsmithmartin@gmail.com
1944, Engelbrecht et al. 2007). The abundance of most tropical vascular plant groups (e.g., epiphytes, herbs, palms, and trees) increases with annual rainfall (Clinebell et al. 1995, Gentry 1995). Lianas (woody vines), however, seem to follow an opposite distribution pattern. Lianas reach maximum relative abundance in seasonally dry tropical forests and decrease in abundance as mean annual rainfall increases (Gentry 1995, Schnitzer 2005, DeWalt et al. 2015). For example, Schnitzer (2005) found that there were five times more lianas in the drier forest compared to the wet forest across the rainfall gradient of the isthmus of Panama. Schnitzer (2005) also 
reported that lianas were considerably more abundant in highly seasonal forests compared to wet forests across a large number of tropical forests, especially compared to trees (Gentry 1991, Swaine and Grace 2007, Dewalt et al. 2010). An explanation for lianas being more abundant relative to trees in seasonal forests is that lianas perform better than trees when water is limited because light is plentiful during dry periods (Schnitzer 2018). This seasonal growth advantage, however, is thought to be lost in aseasonal wet forests, where light is low yearround, thus explaining pan-tropical liana distribution (Schnitzer 2005). For example, in a seasonal forest in Panama, understory lianas were found to grow in height seven times more than understory trees during the dry season, but only two times more during the wet season (Schnitzer 2005). In a more recent and much larger study in Panama, canopy lianas had a far higher growth rate during the dry season than the wet season, whereas trees had the opposite pattern, with a higher growth rate during the wet season than the dry season (Schnitzer and van der Heijden 2019).

There are several potential explanations for the ability of lianas to perform better than trees during seasonal drought. Lianas may grow well during the dry season because they have higher dry season photosynthetic rates, hydraulic conductance, predawn leaf water potential, and more efficient water use compared to trees (Cai et al. 2009, Zhu and Cao 2009, Chen et al. 2015, 2017). Lianas may also access and use water more efficiently than trees (Schnitzer 2005) and may have better developed and deeper root systems than co-occurring trees (Restom and Nepstad 2004), thus, permitting lianas access to deeper sources of water (Andrade et al. 2005, Chen et al. 2015, 2017). Recent studies have also investigated whether trees and lianas differ in hydraulic traits (De Guzman et al. 2016, Werden et al. 2017, van der Sande et al. 2019). For example, van der Sande et al. (2019) found that there was a trade-off between hydraulic efficiency and safety in trees; however, in lianas, hydraulic efficiency was decoupled from hydraulic safety, meaning that lianas potentially have high water conductance and photosynthetic rates while limiting their vulnerability to drought.

An alternative explanation is that lianas have a suite of functional traits that allow them to grow when light is abundant even though water is limited. Lianas tend to be on the fast end of the leaf economic spectrum, with higher specific leaf area (SLA) and foliar nutrient content (Zhu and Cao 2009, Asner and Martin 2012, Wyka et al. 2013, Werden et al. 2017). However, more conservative resource-use strategies, such as higher water use efficiency, denser wood, and lower leaf turgor loss points are associated with greater drought resistance (Bartlett et al. 2014, Reich 2014, Greenwood et al. 2017, O’Brien et al. 2017). Thus, resolving whether lianas and trees differ systematically with respect to both leaf economics and hydraulic traits may help shed light on their distribution patterns and potential responses to global changes such as altered rainfall regimes.
Here we tested the hypothesis that lianas perform better than trees during seasonal drought with a commongarden irrigation experiment. We measured tree and liana water status and photosynthesis throughout the year, as well as functional traits for both lianas and trees (hereafter "growth form"). We predicted that lianas and trees would perform similarly during the wet season, but that during the dry season, lianas would experience less water stress and have higher physiological performance than trees. By contrast, we predicted that, in plots that received dry season irrigation, both lianas and trees would have a similar level of water stress, stomatal conductance, and photosynthesis, which would be more similar to what they experience during the wet season. We predicted that lianas would have greater rooting depth, greater ratio of root length to diameter, better water use efficiency, lower turgor loss point, and less dense wood. We also predicted that dry season irrigation would increase the size of both lianas and trees, but that trees would have a stronger response than lianas, indicating that they suffer more water stress than co-occurring lianas.

\section{Materials ANd Methods}

\section{Experimental design}

In 2011, we established a common garden at Parque Municipal Summit, located near the middle of the rainfall gradient along the isthmus of Panama. The mean annual rainfall at this location is $2,226 \mathrm{~mm}$ and there is a distinct 4-month dry season (months with a rainfall of $<100 \mathrm{~mm}$ ) from December through April (Condit et al. 2000, 2004, Wishnie et al. 2007). In 2011, we established $12,9 \times 9 \mathrm{~m}$ plots that were each separated by at least $5 \mathrm{~m}$ in an open field, and planted replicate seedlings of the same six common species of native lianas (Callichlamys latifolia, Davilla kunthii, Doliocarpus major, Machaerium milleflorum, Maripa panamensis, Paullinia pinnata) and six common species of native trees (Crescentia cujete, Dipteryx oleifera, Hieronyma alchorneoides, Hura crepitans, Swietenia macrophylla, Terminalia amazonia) in all 12 plots (Appendix S1: Table S1). We planted on average five individuals per species per plot for a total of $N=60$ individuals per species. We planted the seedlings in rows within each plot with $1 \mathrm{~m}$ between each seedling in all directions and the order of the individuals was assigned randomly. All focal species were evergreen or brevi-deciduous at this location. We thoroughly irrigated six of the plots with sprinklers at least two days a week throughout the dry season (from January through April), while the six control plots did not receive dry season supplemental irrigation. To irrigate the plots, we used one sprinkler per plot with a spray that reached the entire plot and irrigated with municipal water for approximately six hours per plot, and the soil in the plots was saturated after each watering. We installed trellises for the lianas to climb, and lianas were 
prevented from growing on the trees. We also put trellises next to the trees so that both growth forms would experience the same environmental conditions. We routinely mowed the grass within and around the plots so that herbaceous vegetation would not interfere with the experiment. We allowed the plants to grow for four years, and in February 2015, when many of them had reached reproductive stage and the majority of the lianas were twining and very few of them were freestanding, we started collecting measurements (Appendix S2: Table S1).

\section{Leaf water potential, soil moisture, and gas exchange}

We randomly selected $\sim 24$ individuals of each species (1-2 individuals per plot) on which we measured leaf water status throughout the year. We measured leaf water potential at pre-dawn $\left(\Psi_{\mathrm{PD}}\right)$ and mid-day $\left(\Psi_{\mathrm{MD}}\right)$ on a total of 127 lianas and 100 trees from both irrigated and control plots on five separate sampling times throughout 2015: twice during the dry season (March and April), once during the transition from dry to wet season (May), and twice during the wet season (September and October). We performed these measurements using a 1505D Pressure Chamber Instrument (PMS Instrument Company, Portland, Oregon, USA). Soils were uniform throughout the common garden and appeared to be oxisols. On the same day that we measured leaf water potential, we also measured soil moisture in the top $5 \mathrm{~cm}$ of soil at the base of each individual ( $\sim 24$ measurements per plot) with a soil moisture sensor (SM150, Delta-T Devices, Burwell, UK) in March, April, May, and September. We measured leaf gas exchange with an LI-6400 portable photosynthesis system (Li-Cor, Lincoln, Nebraska, USA) once during the dry season (March) and once during the wet season (October). The $\mathrm{CO}_{2}$ concentration was set to $400 \mu \mathrm{mol} /$ mol, photosynthetic photon flux density was set to $1,200 \mu \mathrm{mol} \cdot \mathrm{m}^{-2} \cdot \mathrm{s}^{-1}$, and the temperature was set to $32^{\circ} \mathrm{C}$. Due to sampling constraints, we were able to take these measurements only for plants in the control plots. Nonetheless, the dry and wet season comparisons between lianas and trees allowed us to test the hypothesis that lianas perform better than trees during the dry season but not the wet season. We calculated intrinsic water use efficiency (iWUE) as the ratio of photosynthetic rate to stomatal conductance $\left(g_{s}\right)$.

\section{Diameter, biomass, and rooting depth and length}

Four years after the treatment began, we measured the diameter (20 $\mathrm{cm}$ from the base) for all individuals in the common garden (12-42 individuals per species per treatment, depending on survival rates at the time of measuring). We harvested above- and belowground biomass of a subsample of individuals from both irrigation treatments, which included all of the species except for Hieronyma alchorneoides. Whole-plant biomass harvests included a total of 12 trees (six from the irrigated and six from the control plots) and 27 lianas (15 from the irrigated and 12 from the control plots). For all the harvested individuals, we weighed all leaves, stems, and coarse roots, and measured root lengths and maximum rooting depth of coarse roots down to diameters of $\sim 5 \mathrm{~mm}$. For each individual, we collected a subsample of leaves, stems, and roots, which we dried at $60^{\circ} \mathrm{C}$ for $>72 \mathrm{~h}$ until they reached constant mass, and then were weighed. Oven-dried masses were used to estimate total dry biomass for each tissue type per individual. We calculated the fraction of total biomass allocated to leaves (leaf mass fraction, LMF), stems (stem mass fraction, $\mathrm{SMF}$ ), and to coarse roots (root mass fraction, RMF). For all of the harvested individuals, we calculated the sum of all root lengths (hereafter root length) and the maximum rooting depth. We also calculated the ratio between root length to the stem diameter at $20 \mathrm{~cm}$ from the base.

\section{Leaf chemistry, specific leaf area, and hydraulic traits}

We chose one individual from three of the irrigated plots and one from three of the control plots for all trait measurement (six individuals per species). We measured leaf carbon (C), nitrogen $(\mathrm{N})$, and $\mathrm{C}$ stable isotopic concentrations $\left(\delta^{13} \mathrm{C}\right)$ on an Isotope Ratio Mass Spectrometer at the Smithsonian Tropical Research Institute Soils Laboratory in Panama. We collected the leaves during the wet season and, depending on leaf size, we ground, bulked, and analyzed three to five leaves per individual. We used the stable isotope of carbon, $\delta^{13} \mathrm{C}$, as a proxy for integrated water use efficiency (WUE). We obtained specific leaf area (SLA) by measuring leaf area including petioles on three leaves from each of the chosen individuals using an LI-3100C Area Meter (Li-Cor). We then quantified leaf dry mass by drying each leaf at $60^{\circ} \mathrm{C}$ until it reached constant mass. We calculated SLA $\left(\mathrm{cm}^{2} / \mathrm{g}\right)$ as the leaf area divided by dry leaf mass, and we calculated the average of three measurements per individual plant.

We calculated leaf turgor loss point (TLP) using the bench dry method to measure pressure-volume curves as described in Tyree and Hammel (1972). For each species, we created TLP curve for three individuals from the irrigated plots and three from the control plots. We selected each individual from a different plot. From the pressure-volume curves, we calculated leaf relative water content at TLP $\left(\mathrm{RWC}_{\mathrm{TLP}}\right)$, leaf capacitance at TLP $\left(\mathrm{C}_{\mathrm{TLP}}\right)$, and absolute capacitance at full turgor $\left(\mathrm{AC}_{\mathrm{FT}}\right.$; Ewers et al. 1997, Sack et al. 2003). All hydraulic trait measurements were made during the wet season on fully expanded healthy leaves.

We quantified stem and root wood density for all the harvested individuals following Chave et al. (2006). Specifically, stem and root wood density (WD) were calculated as the ratio of dry mass to fresh volume $\left(\mathrm{g} / \mathrm{cm}^{3}\right)$. We collected fresh wood samples immediately after harvesting and estimated their volume as the mass of water 
needed to displace the sample. We then dried the samples at $60^{\circ} \mathrm{C}$ until they reached constant mass and weighed them.

\section{Data analysis}

Our experimental design allowed for comparisons of response variables that were collected multiple times (i.e., soil moisture, plant water status) between both seasons and irrigation treatments. For soil moisture, we used a mixed model with irrigation treatment (irrigated and control), and sampling time (month) as fixed effects and plot as a random effect (Appendix S2: Table S1). For $\Psi$, we calculated diurnal regulation as $\Delta \Psi\left(\Psi_{\mathrm{MD}}-\right.$ $\left.\Psi_{\mathrm{PD}}\right) . \Psi_{\mathrm{PD}}, \Psi_{\mathrm{MD}}$, and $\Delta \Psi$ were analyzed using mixed models with irrigation treatment, growth form (liana and tree), and sampling time as fixed effects and species and individual as random effects (Appendix S2: Table S1). We analyzed photosynthetic rates, $g_{\mathrm{s}}$, and iWUE using a mixed effects model with season (dry and wet) and growth form as fixed effects and species and individual as random effects (Appendix S2: Table S1).

For variables that we measured once at the end of the experiment (i.e., stem diameter at $20 \mathrm{~cm}$, total biomass, LMF, SMF, RMF, maximum rooting depth, root length, ratio of root length to stem diameter), we used mixed models with growth form and irrigation treatment as fixed effects and species as a random effect (Appendix S2: Table S1). We log-transformed stem diameter at $20 \mathrm{~cm}$, total biomass, maximum rooting depth, sum of root length, and the ratio of root length to stem diameter to account for the orders of magnitude of difference in the data. Because of the large difference in biomass among focal species, we calculated the mean irrigation enhancement of biomass for each species as follows:

Irrigation enhancement of biomass $=$ $\mu$ biomass irrigated $-\mu$ biomass control

$\mu$ biomass control

where $\mu$ is the species mean.

We compared the irrigation enhancement of biomass between growth forms using a mixed model with growth form as a fixed effect and species as a random effect. We log-transformed the data because of the large differences in biomass among species. One of the species (Machaerium milleflorum) responded negatively to irrigation, so we added 1 to all of the data to yield positive values prior to log transformation. Irrigation treatment did not have a significant effect on the following response variables: SLA, percent N, C:N ratio, WUE, TLP, $\mathrm{RWC}_{\mathrm{TLP}}$, $\mathrm{C}_{\mathrm{TLP}}, \mathrm{AC}_{\mathrm{FT}}$, stem $\mathrm{WD}$, and root $\mathrm{WD}$, therefore, for these variables we used mixed models with only growth form as a fixed effect and species as a random effect (Appendix S2: Table S1). We log-transformed SLA. All analyses were performed in $\mathrm{R}$ (Version 3.3.3). We conducted all the mixed models using the nlme $\mathrm{R}$ package
(Pinheiro et al. 2018) and used $Q-Q$ plots to examine the distribution of residuals. We used least squares means pairwise comparisons with the lsmeans R package (Russell 2016) to interpret significant differences among main effects.

\section{Results}

\section{Soil moisture}

The supplemental irrigation treatment increased soil moisture in the irrigated plots $\left(F_{1,10}=8.56, P=0.015\right)$. During the dry season, mean percent soil moisture in the irrigated plots was $4.4 \%$ higher in March than the control plots $(24.86$ vs. $20.51 \% ; \quad t=2.93, \quad \mathrm{df}=10$, $P=0.015)$, and $2.7 \%$ higher in April (22.32 vs. $19.60 \%$; $t=1.94, \mathrm{df}=10, P=0.081$ ). There was dramatic seasonal variation in soil moisture throughout the year $\left(F_{3,885}=742.26, P<0.001\right)$, although this was less pronounced in the irrigated plots (Appendix S3: Fig. S1). However, no irrigation treatment was applied during the wet season and there was no significant difference between the irrigated and control plots during May $(27.00 \%$ vs. $25.39 \%$, respectively; $t=1.24, \mathrm{df}=10$, $P=0.24)$ and September $(45.74 \%$ vs. $44.04 \%$, respectively; $t=1.30 \mathrm{df}=10, P=0.22$ ).

\section{Leaf water potential}

During the wet season (May, September, and October), lianas and trees had similar $\Psi_{\mathrm{PD}}$ (Fig. 1a). During the dry season, however, lianas in the control plots had significantly higher (less negative) water status than trees (higher $\Psi_{\mathrm{PD}}, F_{4,781}=9.26, P<0.001$, Fig. 1a; Appendix S4: Table S1). The largest difference between liana and tree water status occurred for the pre-dawn water potential at the end of the dry season (in April), where the mean $\Psi_{\mathrm{PD}}$ of lianas in control plots was $54 \%$ higher than trees in control plots $(-0.92$ vs. $-1.42 \mathrm{MPa}$, respectively). Lianas in the irrigated plots were also less water stressed than the trees in the irrigated plots during the dry season but the difference was slightly lower than in the control plots (Fig. 1a; Appendix S4: Table S1), with the lianas in irrigated plots having only $43 \%$ higher mean values than trees in irrigated plots in April ( -0.83 vs. $-0.58 \mathrm{MPa}$ respectively). Lianas also had higher (less negative) midday dry-season water potentials $\left(\Psi_{\mathrm{MD}}\right)$ than trees in the control plots, an effect that disappeared with the irrigation treatment. Both lianas and trees in irrigated plots had less negative $\Psi_{\mathrm{MD}}$ than the ones in the control plots during the dry season $\left(F_{1}\right.$, $235=18.49, \quad P<0.001, \quad$ Fig. $1 b ; \quad$ Appendix $\quad$ S5: Table S1), indicating that the irrigation treatment affected plant water status. These findings suggest that lianas were far less water stressed than the tress in the control plots, and that trees responded more to dry season irrigation than did lianas. Indeed, mean $\Delta \Psi$ was higher for lianas than trees at each measurement period; 

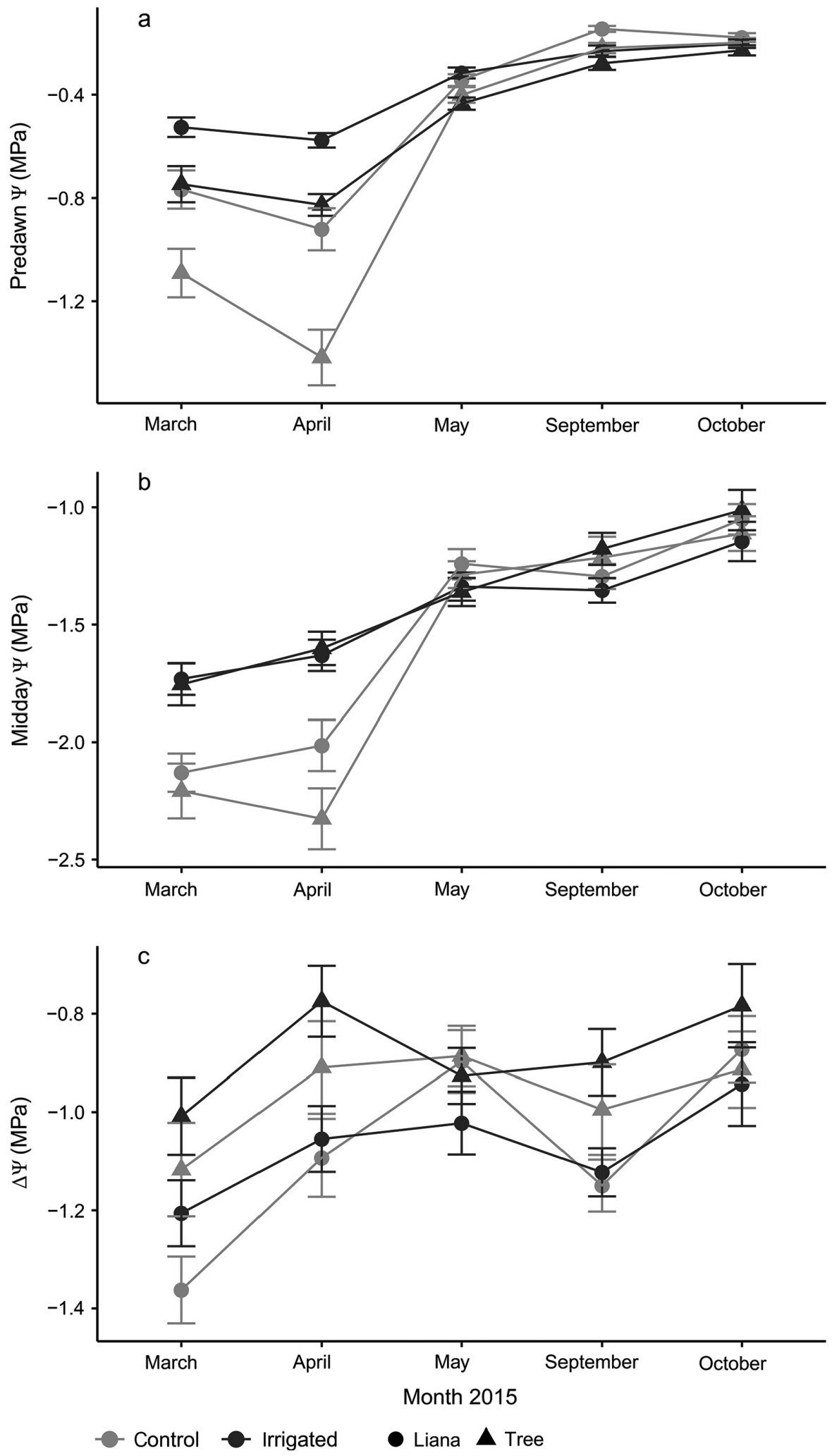

FIG. 1. (a) Predawn, (b) midday, and (c) the difference between predawn and midday leaf water potential $\Psi$ of lianas and trees in irrigated and control plots measured on the same individuals two times during the dry season (March and April), once during the transition from dry to wet (May), and two times during the wet season (September and October). Error bars are standard error. 
however, these differences were not statistically significant $\left(F_{1,235}=0.76, P=0.383\right.$; Fig. $\left.1 \mathrm{c}\right)$.

\section{Plant diameter, biomass, and rooting dynamics}

Trees grew more in response to irrigation than did lianas $\left(F_{1,597}=9.84, P=0.002\right.$; Fig. $\left.2 \mathrm{a}\right)$, with trees in irrigated plots having on average $15 \%$ larger diameters than the trees in control plots $(t=3.58, \mathrm{df}=597, P<0.001)$. By contrast, mean liana diameter did not differ between irrigated and control plots $(t=0.87, \quad \mathrm{df}=597$, $P=0.383$ ). Trees in irrigated plots also had much greater biomass than trees in control plots, whereas lianas had similar biomass independent of irrigation treatment. Mean tree biomass in the irrigated plots was 119\% greater than tree biomass in the control plots, whereas liana biomass in the irrigated plots was only $26 \%$ greater than liana biomass in the control plots (Fig. 2b). Variation in biomass was high among individuals and plots; nevertheless, the growth form by irrigation treatment interaction was marginally significant $\left(F_{1,26}=3.51\right.$, $P=0.072$ ). Calculated irrigation enhancement of biomass was greater for trees than for lianas, but this difference was not statistically significant. Lianas in control plots allocated $33.5 \%$ more of their biomass to leaves than the lianas in irrigated plots $\left(F_{1,26}=7.91\right.$, $P=0.009 ; t=2.81, \mathrm{df}=26, P=0.043$; Appendix S6: Fig. S1a), whereas the irrigated lianas allocated $11.5 \%$ more biomass to stems (although this trend was not statistically significant; Appendix S6: Fig. S1b). Independent of irrigation treatment, lianas allocated similar fractions of their biomass to roots (Appendix S6: Fig. S1c). By contrast, trees allocated similar proportions of their total biomass to leaves independent of irrigation treatment (Appendix S6: Fig. S1a). For allocation to roots, there was a significant interaction between growth form and irrigation treatment $\left(F_{1,26}=4.558\right.$, $P=0.042$ ), with lianas allocating similar fractions of biomass to roots independent of irrigation treatment, whereas trees allocated more biomass to roots when they were unirrigated. The irrigation treatment revealed a trade-off between allocation to stems vs. roots for trees; trees in the control treatment allocated on average 38\% more to roots at the expense of stems $(t=2.75, \mathrm{df}=26$, $P=0.050$; Appendix S6: Fig. S1c), while the opposite pattern was true for trees in the irrigated treatment, with a

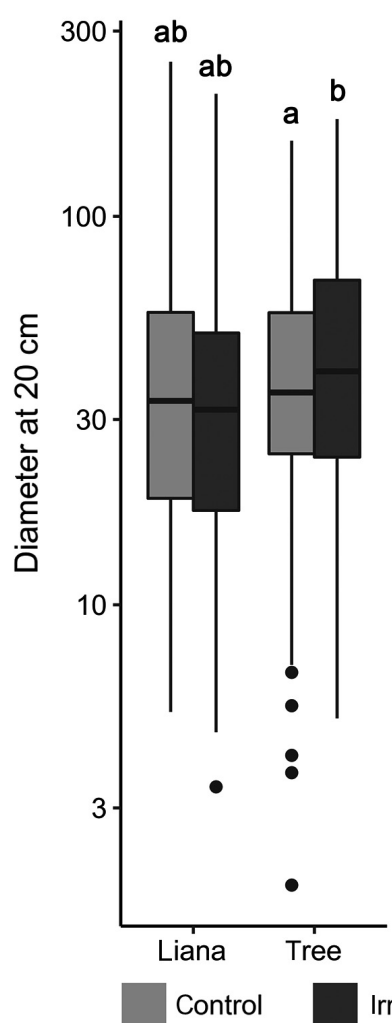

b

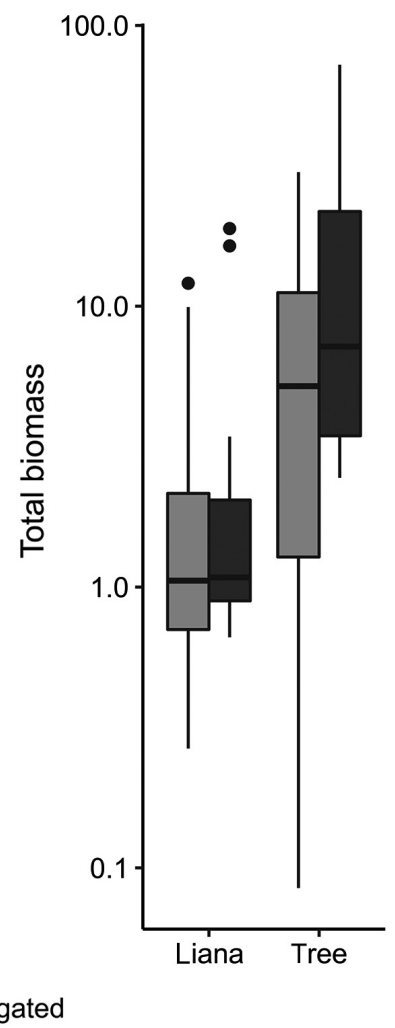

C

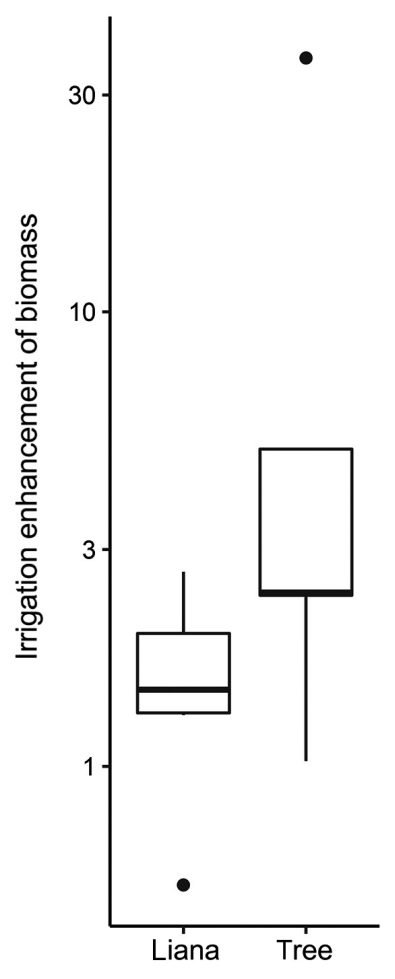

FIG. 2. (a) Diameter measured at $20 \mathrm{~cm}$ from the base $(\mathrm{mm})$ and (b) total biomass $(\mathrm{kg})$ of lianas and trees grown in irrigated and control plots. (c) Irrigation enhancement $(\mathrm{g} / \mathrm{g})$ of biomass of all harvested individuals calculated as ([mean biomass of individuals in irrigated plots] - [mean biomass of individuals in control plots] $) /($ mean biomass of individuals in control plots). All data have been log-transformed. Different letters indicate significant differences $(P<0.05)$. Box plot midlines are medians. box edges are first and third quartiles, whiskers are the minimums and maximums, and points are outliers. 
a

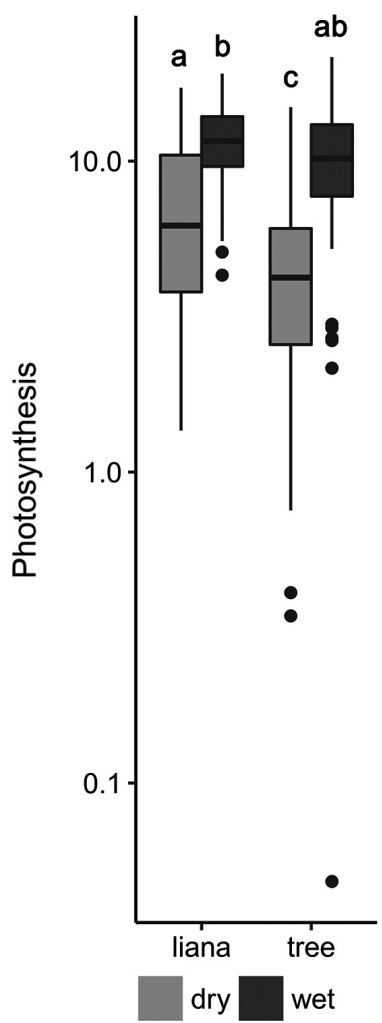

b

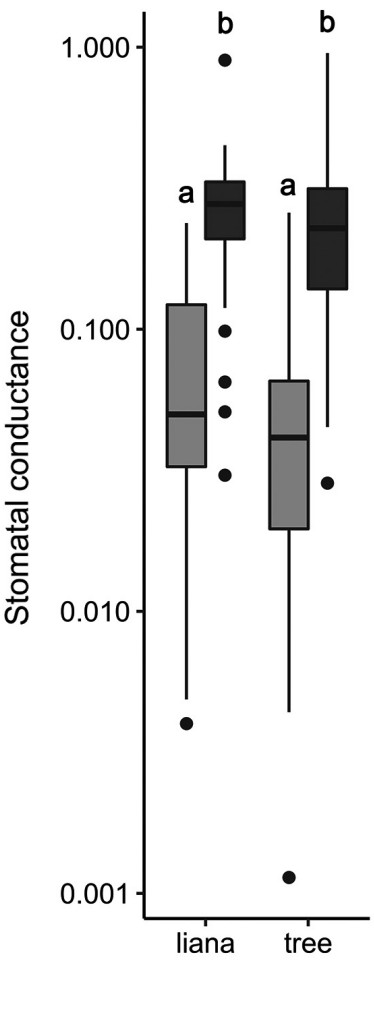

c

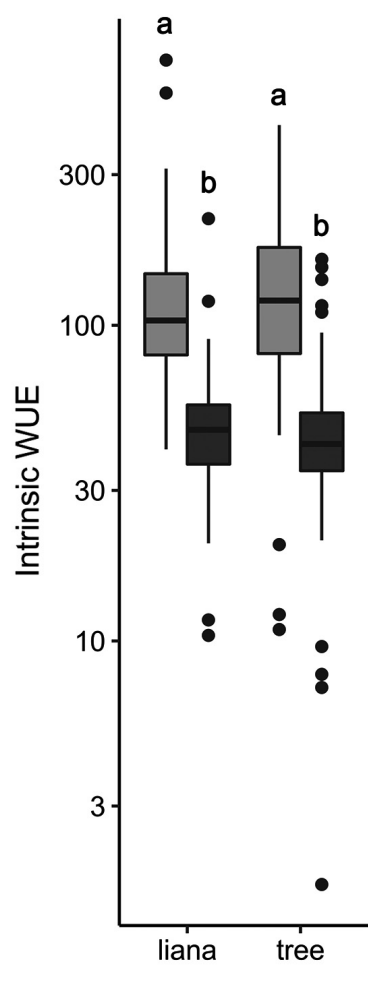

FIG. 3. (a) Photosynthesis rates $\left(\mu \mathrm{mol} \mathrm{CO} \mathrm{CO}_{2} \cdot \mathrm{m}^{-2} \cdot \mathrm{s}^{-1}\right)$, (b) stomatal conductance $\left(\mathrm{mol} \mathrm{H}_{2} \mathrm{O} \cdot \mathrm{m}^{-2} \cdot \mathrm{s}^{-1}\right)$, and (c) intrinsic water use efficiency (WUE; $\left(\mu \mathrm{mol} \mathrm{CO} / \mathrm{mol} \mathrm{H}_{2} \mathrm{O}\right)$ of lianas and trees in control plots during the dry season (dry) and the wet season (wet). All data have been log-transformed. Letters indicate significant differences $(P<0.05)$. Box plot mid-lines are medians. box edges are first and third quartiles, whiskers are the minimums and maximums, and points are outliers.

$20 \%$ greater allocation to stems (although this trend was not statistically significant; Appendix S6: Fig. S1b).

Despite clear differences in biomass, growth, and allocation, rooting depth showed no significant difference between growth forms $\left(F_{1,9}=0.86, P=0.377\right)$ or irrigation treatment $\left(F_{1,26}=0.15, P=0.700 ;\right.$ Appendix S7: Fig. S1a). For root length, there was no significant effect of between growth form, irrigation treatment, and the interaction between growth form and irrigation treatment $\left(F_{1,19}=3.48, P=0.078\right.$; Appendix S7: Fig. S1b). However, lianas had a greater ratio of root length to stem diameter in both control and irrigated plots $\left(F_{1,9}=17.14\right.$, $P=0.003$; Appendix S7: Fig. S1c), suggesting that lianas allocate more to root length for a given stem diameter compared to trees in the control plots.

\section{Photosynthesis and water use efficiency}

Both lianas and trees had higher photosynthetic rates during the dry season than the wet season $\left(F_{1,105}=31.30, P<0.001\right.$, Fig. 3a). Lianas had higher photosynthetic rates than trees during both seasons $\left(F_{1,105}=8.19, P=0.005\right)$; however, the magnitude of these differences varied seasonally. During the dry season, lianas had $45 \%$ higher photosynthetic rates than trees $(t=2.86$, df $=105, \quad P=0.024)$, but only $17 \%$ higher photosynthetic rates during the wet season $(t=2.06, \mathrm{df}=105, P=0.178)$. That is, photosynthetic rate decreased significantly more for trees than for lianas during the dry season (Fig. 3a). Both lianas and trees had higher $g_{\mathrm{s}}\left(F_{1,105}=136.42, P<0.001\right.$, Fig. 3b) during the wet season, and higher iWUE $\left(F_{1,105}=81.06\right.$, $P<0.001$; Fig. 3c) during the dry season.

\section{Specific leaf area, leaf chemistry, and hydraulic traits}

Aside from SLA, there were no differences in functional traits between growth forms. On average, trees had higher SLA than lianas (122.53 vs. $91.54 \mathrm{~cm}^{2} / \mathrm{g}$, respectively; $F_{1,12}=10.66, \quad P=0.009 ;$ Appendix S8: Table S1). However, lianas and trees did not differ significantly in foliar $\mathrm{N}$ concentrations, foliar $\mathrm{C}: \mathrm{N}$ ratios, WUE, turgor loss point, relative water content at turgor loss point, capacitance at turgor loss point, absolute capacitance at turgor loss point, and wood densities of stems and roots (Appendix S8: Table S1). The lack of significant difference in foliar $\mathrm{N}, \delta^{13} \mathrm{C}, \mathrm{TLP}$, and wood density between lianas and trees limits our ability to 
array trees and lianas along the acquisitive-conservative trait continuum, thus we do not discuss these results further. One potential reason why we did not find any differences among liana and tree TLP is because we conducted these measurements in the wet season, and not in the dry season, as has been done in other studies when a greater range of value among species has been found (Maréchaux et al. 2015, 2017).

\section{Discussion}

Our experiment is the first to examine the long-term effects of dry season irrigation on lianas and trees in a highly controlled environment (e.g., all individuals had the same age and access to similar levels of light in the open-field common garden). Our study is also the first to examine how dry season irrigation affects plant growth with a whole plant harvest after four years of treatment. One of our key findings was that lianas were able to maintain higher photosynthetic levels while experiencing less drought stress than co-occurring trees during the dry season. Another key finding was that trees responded more to irrigation than the lianas by growing far more in terms of diameter and total biomass, which also suggests that the trees were more drought stressed during the dry season than were lianas. Our final key findings were that lianas had greater ratio of root length to diameter than control trees; however, contrary to what we expected, lianas were not deeper rooted, did not have better water use efficiency, lower turgor loss point, and less dense wood than trees.

\section{Liana and tree response to seasonal drought}

The response of trees to dry-season irrigation indicates that trees in this study were limited by soil moisture during the dry season. By contrast, lianas in this study did not respond to increased soil moisture, and yet were able to maintain higher water potential (Fig. 1) and photosynthesis (Fig. 3a) than trees during the dry season without dry season irrigation. The combination of higher photosynthesis levels and greater physiological regulation (stomatal control) could allow lianas to function more efficiently than trees when water is limited during seasonal drought. The ability of lianas to perform better than competing trees during seasonal drought gives lianas a seasonal growth advantage over trees in seasonal forests that they lack in wet forests, thus explaining higher liana abundance in seasonal forests because they have an extra 3 to 5 months of growth that they lack in ever-wet forests (Schnitzer 2005, 2018). Our results (Fig. 2) are consistent with Schnitzer (2005), who also found that lianas grew more than trees when water was limited. Similarly, in a recent study of $>1,100$ canopy trees and >800 canopy lianas in central Panama, Schnitzer and van der Heijden (2019) reported that liana growth rate was higher during the dry season than the wet season in each of the five years of their study, and that lianas grew as much during the $\sim 4$-month dry season as they did during the $\sim 8$-month wet season. By contrast, they found that tree growth rate was far higher during the wet season, and that trees grew far more during the 8-month wet season than the 4-month dry season.

Our results are also consistent with previous studies that reported that lianas maintained better plant water status (Fig. 1a) and higher rates of photosynthesis (Fig. 3a) during seasonal drought than trees. For example, Zhu and Cao (2009) found that lianas growing in a seasonal tropical rainforest in China had less negative predawn leaf water potential at the end of the dry season than co-occurring trees. Chen et al. (2015) also found that during the dry season, in the karst forest in Xishuangbanna in Southwest China, lianas had much higher predawn leaf water potential than trees. In our study, however, trees responded to the irrigation treatment whereas lianas did not (Fig. 2), demonstrating that the trees were more drought stressed than the lianas, and that this drought stress was caused, in part, by limited soil moisture. Maintaining plant water status during seasonal drought, when light levels are high, could permit lianas to perform better than trees in seasonal forests. In our study, lianas had higher rates of photosynthesis than co-occurring trees during seasonal drought (Fig. 3a) similar to Cai et al. (2009). However, based on our results, higher photosynthesis in lianas compared to trees appears to be diminished when water is readily available. The combination of maintaining healthy water status and being able to maximize photosynthesis during the dry season, when light is plentiful, could explain why lianas reach highest relative abundance in seasonally dry tropical forests compared to wetter forests (Schnitzer 2018).

\section{Root dynamics of lianas and trees}

Previous studies suggested that lianas may grow better during seasonal drought because of deep root systems (Schnitzer 2005). For example, Restom and Nepstad (2004) had found that 15-yr-old lianas of one of the same species that we used in our experiment (Davilla kunthii) had roots up to $10 \mathrm{~m}$ deep. However, Restom and Nepstad (2004) did not excavate co-occurring trees, thus, it is difficult to determine whether lianas had deeper rooting depths compared to trees in their study. In the karst forest of Southwest China, Chen et al. (2015) found that, during the dry season, lianas used deeper soil water than co-occurring trees based on hydrogen stable isotope concentrations in xylem water. By contrast, we found that lianas had similar rooting depths as trees (Appendix S7: Fig. S1a), and were not deeper rooted as we had predicted. Johnson et al. (2013) also found that lianas did not have deeper roots than a co-occurring tree species in a nearby forest in Panama. Other studies using stable isotopes found evidence that lianas were not using deep sources of water. For example, two studies conducted in Panama, in which stable isotopes of hydrogen 
were used to track water use in lianas and trees, found that lianas shifted to deeper water sources during the dry season whereas large trees did not; however, deeper sources of water was only measured at $\sim 60 \mathrm{~cm}$ (Meinzer et al. 1999, Andrade et al. 2005). De Deurwaerder et al. (2018) used stable isotopes of hydrogen and oxygen and found that lianas used more superficial water in than trees during the dry season in a rainforest in French Guiana.

Our findings were similar in that we found that lianas were able to maintain water status better than trees during the dry season without having deeper roots. Apparently, extracting water from $\sim 20$ to $100 \mathrm{~cm}$ depth in the soil profile was deep enough to maintain relatively healthy water status and function throughout the dry season at this location (Appendix S7: Fig. S1a). The absolute rooting depth of plants may not be the most important predictor of the ability of plants to take up water, and rooting depth likely depends on where the extractable water is located at a given site, which can change considerably with soil type and the geology of the site (Manzané-Pinzón et al. 2018).

Root length may also contribute to water access and uptake when water is limited. In our study, lianas had greater ratios of root lengths to diameter than the trees in the control plots, independent of irrigation treatment (Appendix S7: Fig. S1c), which suggests that lianas were able to access greater soil volumes and potentially more water relative to their size than the drought-stressed trees. Thus, lianas may rely on more extensive root systems with more lateral roots to maintain water status during seasonal drought. Lianas did not alter their root growth patterns in relation to the irrigation treatment, whereas trees did (Appendix S7: Fig. S1c), providing additional evidence that the alleviation of soil water limitation has less of an effect on lianas than trees. By contrast, we found that trees in the control plots allocated greater proportions of their biomass to roots than the ones in the irrigated plots, likely to increase water uptake (Appendix S6: Fig. S1c). Our findings for tree allocation patterns in response to dry season irrigation is consistent with earlier hypothesis (Bloom et al. 1985), which suggests that plants will trade the higher carbon cost of root production to increase water acquisition capacity when water is limited.

\section{Liana growth patterns and forest carbon storage}

The ability of lianas to grow well during drought may explain why lianas are increasing in abundance and biomass in tropical forests. The pattern of increasing liana abundance was first documented in non-fragmented old growth Amazonian forests, where Phillips et al. (2002) discovered that, over a 20 -yr period, lianas had increased in density, basal area, and size, with the increase becoming greater over time. Ingwell et al. (2010) found that the proportion of tree canopies infested with lianas in the seasonal tropical moist forest on Barro Colorado Island in Panama had increased from $32 \%$ to $75 \%$ in the last 50 yr. Laurance et al. (2014) also found that over a 14$\mathrm{yr}$ period in an undisturbed rainforest in central Amazon, liana abundance increased by $1 \%$ per year. Subsequent studies have also presented evidence to support increases in lianas abundance, biomass, or dominance across Neotropical forests (Wright et al. 2004, Yorke et al. 2013, Hogan et al. 2017), reviewed by Schnitzer and Bongers (2011) and Schnitzer (2015).

One of the potential explanations for the increase in liana abundance in neotropical forests relative to trees is more intense and prolonged droughts (Schnitzer and Bongers 2011, Schnitzer 2015). Rainfall patterns in some tropical forests have been shifting, leading to an increase in the length and severity of seasonal drought and a decrease in rainfall (Feng et al. 2013), and these trends are predicted to continue (Phillips 2009, Lee and McPhaden 2010, Dai 2013). For example, in Panama, where liana abundance appears to be increasing (Wright et al. 2004, Schnitzer et al. 2012) annual precipitation has decreased by nearly $20 \%$ during the last century (Schnitzer 2005, Schnitzer and Bongers 2011). One hypothesis for an increase in lianas relative to trees is that a rise in evapotranspirative demand caused by increases in seasonality and temperature, coupled with a reduction of precipitation, can give a competitive advantage to lianas over trees (Schnitzer and Bongers 2011). Thus, because lianas are less water stressed than trees, rising seasonality together with decreases in rainfall could be more detrimental to trees, giving lianas a competitive advantage and permitting their numbers and size to increase.

Increases in liana abundance can affect forest-level carbon storage. For example, van Der Heijden et al. (2015) found that liana competition with trees reduced forest carbon uptake by $\sim 76 \%$, while other studies have documented $84 \%$ reductions in carbon uptake (van der Heijden and Phillips 2009). Furthermore, because lianas use trees for support, it is thought that lianas are able to invest less biomass in their stems and therefore do not make up for the biomass that they displace in trees, leading to an overall reduction in forest carbon uptake and storage (Schnitzer and Bongers 2002, Ingwell et al. 2010, van der Heijden et al. 2013, van Der Heijden et al. 2015). For example, in a liana removal experiment in treefall gaps in Panama, lianas contributed only $24 \%$ of the total aboveground biomass that they displaced in trees (Schnitzer et al. 2014). Thus, increases in seasonality could lead to an overall reduction in forest carbon storage caused by a reduction in tree biomass due to drought stress and coupled with further tree biomass reduction due to increased competition with lianas.

Differential patterns of biomass allocation to tissues like leaves, stems, and roots between lianas and trees may alter forest-level carbon stocks and fluxes. Previous studies reported that lianas allocate more biomass to leaves, while trees allocate more to stems (Cai et al. 2007, van der Heijden et al. 2013). However, our results show that increases in seasonality due to climate change 
could cause lianas to allocate more biomass to leaves, whereas trees to allocate less to stems in favor of roots (Appendix S6: Fig. S1). Any consequent increases in allocation to leaves, which have a more rapid turnover time compared to other tissues (Powers et al. 2009), and a decrease in allocation to stems, may reduce net tropical forest carbon storage capacity (Galbraith et al. 2013). For example, in a large-scale liana removal experiment, van Der Heijden et al. (2015) found that forest areas with lianas have higher biomass allocation to leaves, whereas forest areas in which lianas had been experimentally removed had higher allocation to stems. Furthermore, as lianas increase investment into leaves, they may compete more intensely with trees for light and belowground resources, further suppressing carbon uptake by trees. Thus, decreases in rainfall and rising liana densities could shift forest biomass allocation toward a greater proportion of leaves instead of stems leading to a reduction in total forest carbon storage. These findings have broad implications for forest-level carbon storage in the face of increasing drought.

In conclusion, our findings suggest that lianas capitalize on seasonal drought via higher photosynthetic performance while limiting water stress. By contrast, trees suffer more from water stress, which appears to limit their photosynthetic performance. The ability of lianas to grow exceptionally well (and better than trees) during seasonal drought gives lianas a seasonal growth advantage, which could explain why liana abundance peaks in highly seasonal forests. Furthermore, the ability of lianas to perform well during stronger droughts may explain increasing liana abundance in tropical forests. Interestingly, we found that lianas and trees have similar rooting depths; nonetheless, lianas were still able to maintain higher rates of photosynthesis and healthier water status compared to trees without tapping into exceptionally deeper sources of water. Collectively, our findings help shed light on how lianas and trees vary in their life-history strategies and respond differently to drought, which ultimately may explain the unique distribution patterns of lianas and trees.

\section{ACKNOWLEDGMENTS}

We thank Maria M. Garcia-Leon, Boris Bernal, Abelino Valdez, Silfredo Tascon, Felipe Mello, Jeremy La Che, and Dathan Lythgoe for their contributions to planting, irrigation, maintenance, and harvesting of the common garden. Financial support was provided by NSF-DEB 0845071 , NSF-DEB 1822473 , NSF-IOS 1558093 (to S. A. Schnitzer), NSF-DDIG 1700855 (to C. M. Smith-Martin), UMN Carolyn Crosby Research Grant and Natural History Award from the Dayton Bell Museum Fund (to C. M. Smith-Martin), and a National Researcher award from Sistema Nacional de Investigación of the Republic of Panamá (to O. R. Lopez).

\section{Literature Cited}

Andrade, J. L., F. C. Meinzer, G. Goldstein, and S. A. Schnitzer. 2005. Water uptake and transport in lianas and co-occurring trees of a seasonally dry tropical forest. Trees 19:282-289.

Asner, G. P., and R. E. Martin. 2012. Contrasting leaf chemical traits in tropical lianas and trees: implications for future forest composition. Ecology Letters 15:1001-1007.

Bartlett, M. K., Y. Zhang, N. Kreidler, S. Sun, R. Ardy, K. Cao, and L. Sack. 2014. Global analysis of plasticity in turgor loss point, a key drought tolerance trait. Ecology Letters 17:1580 1590.

Beard, J. S. 1944. Climax vegetation in tropical America. Ecology 25:127-158.

Bloom, A. J., F. S. Chapin, and H. A. Mooney. 1985. Resource Limitation in Plants - An Economic Analogy. Annual Review of Ecology and Systematics 16:363-392.

Cai, Z. Q., L. Poorter, K. F. Cao, and F. J. J. M. Bongers. 2007. Seedling growth strategies in Bauhinia species: comparing lianas and trees. Annals of Botany 100:831-7364.

Cai, Z. Q., S. A. Schnitzer, and F. Bongers. 2009. Seasonal differences in leaf-level physiology give lianas a competitive advantage over trees in a tropical seasonal forest. Oecologia $161: 25-33$.

Chave, J., H. C. Muller-Landau, T. R. Baker, T. A. Easdale, H. T. Steege, and C. O. Webb. 2006. Regional and phylogenetic variation of wood density across 2456 neotropical tree species. Ecological Applications 16:2356-2367.

Chen, Y.-J., K.-F. Cao, S. A. Schnitzer, Z.-X. Fan, J.-L. Zhang, and F. Bongers. 2015. Water-use advantage for lianas over trees in tropical seasonal forests. New Phytologist 205:128136.

Chen, Y.-J., S. A. Schnitzer, Y.-J. Zhang, Z.-X. Fan, G. Goldstein, K. W. Tomlinson, H. Lin, J.-L. Zhang, and K.-F. Cao. 2017. Physiological regulation and efficient xylem water transport regulate diurnal water and carbon balances of tropical lianas. Functional Ecology 31:306-317.

Clinebell, R. R., O. L. Phillips, A. H. Gentry, N. Stark, and H. Zuuring. 1995. Prediction of neotropical tree and liana species richness from soil and climatic data. Biodiversity \& Conservation 4:56-90.

Condit, R., K. Watts, S. A. Bohlman, R. Pérez, R. B. Foster, and S. P. Hubbell. 2000. Quantifying the deciduousness of tropical forest canopies under varying climates. Journal of Vegetation Science 11:649-658.

Condit, R., S. Aguilar, A. Hernandez, R. Perez, S. Lao, G. Angehr, S. P. Hubbell, and R. B. Foster. 2004. Tropical forest dynamics across a rainfall gradient and the impact of an El Nino dry season. Journal of Tropical Ecology 20:51-72.

Dai, A. 2013. Increasing drought under global warming in observations and models. Nature Climate Change 3:171-171.

De Deurwaerder, H., P. Hervé-Fernández, C. Stahl, B. Burban, P. Petronelli, B. Hoffman, D. Bonal, P. Boeckx, and H. Verbeeck. 2018. Liana and tree below-ground water competition - evidence for water resource partitioning during the dry season. Tree Physiology 38:1071-1083.

De Guzman, M. E., L. S. Santiago, S. A. Schnitzer, and L. Álvarez-Cansino. 2016. Trade-offs between water transport capacity and drought resistance in neotropical canopy liana and tree species. Tree Physiology 37:1404-1414.

van Der Heijden, G. M. F., J. S. Powers, and S. A. Schnitzer. 2015. Lianas reduce carbon accumulation and storage in tropical forests. Proceedings of the National Academy Sciences of USA 112:13267-13271.

Dewalt, S. J., et al. 2010. Annual rainfall and seasonality predict pan tropical patterns of Liana density and basal area. Biotropica 42:309-317.

DeWalt, S. J., et al. 2015. Biogeographical patterns of liana abundance and diversity. Pages 131-146 in S. A. Schnitzer, F. 
Bongers, R. J. Burnham, and F. E. Putz, editors. Ecology of lianas. John Wiley \& Sons, West Sussex, UK.

Engelbrecht, B. M. J., L. S. Comita, R. Condit, T. A. Kursar, M. T. Tyree, B. L. Turner, and S. P. Hubbell. 2007. Drought sensitivity shapes species distribution patterns in tropical forests. Nature 447:80.

Ewers, F. W., M. R. Carlton, J. B. Fisher, K. J. Kolb, and M. T. Tyree. 1997. Vessel diameters in roots versus stems of tropical lianas and other growth forms. IAWA Journal 18:261-279.

Feng, X., A. Porporato, and I. Rodriguez-Iturbe. 2013. Changes in rainfall seasonality in the tropics. Nature Climate Change $3: 811$.

Galbraith, D., et al. 2013. Residence times of woody biomass in tropical forests. Plant Ecology \& Diversity 6:139-157.

Gentry, A. H. 1991. The distribution and evolution of climbing plants. Pages 3-50 in F. E. Putz and H. A. Mooney, editors. The biology of vines. Cambridge University Press, Cambridge, UK

Gentry, A. H. 1995. Diversity and floristic composition of Neotropical dry forests. Pages 146-194 in S. H. Bullock, H. A. Mooney, and E. Medina, editors. Seasonally dry tropical forests. Cambridge University Press, Cambridge, UK.

Greenwood, S., et al. 2017. Tree mortality across biomes is promoted by drought intensity, lower wood density and higher specific leaf area. Ecology Letters 20:539-553.

Hogan, J. A., S. Mayorquín, K. Rice, J. Thompson, J. K. Zimmerman, and N. Brokaw. 2017. Liana dynamics reflect landuse history and hurricane response in a Puerto Rican forest. Journal of Tropical Ecology 33:155-164.

Ingwell, L. L., S. Joseph Wright, K. K. Becklund, S. P. Hubbell, and S. A. Schnitzer. 2010. The impact of lianas on 10 years of tree growth and mortality on Barro Colorado Island, Panama. Journal of Ecology 98:879-887.

Johnson, D. M., J. C. Domec, D. R. Woodruff, K. A. McCulloh, and F. C. Meinzer. 2013. Contrasting hydraulic strategies in two tropical lianas and their host trees. American Journal of Botany 100:374-383.

Laurance, W. F., A. S. Andrade, A. Magrach, J. L. C. Camargo, J. J. Valsko, M. Campbell, P. M. Fearnside, W. Edwards, T. E. Lovejoy, and S. G. Laurance. 2014. Long- term changes in liana abundance and forest dynamics in undisturbed Amazonian forests. Ecology 95:1604-1611.

Lee, T., and M. J. McPhaden. 2010. Increasing intensity of El Niño in the central-equatorial Pacific. Geophysical Research Letters 37:1-5.

Manzané-Pinzón, E., G. Goldstein, and S. A. Schnitzer. 2018. Does soil moisture availability explain liana seedling distribution across a tropical rainfall gradient? Biotropica 50:215224.

Maréchaux, I., M. K. Bartlett, L. Sack, C. Baraloto, J. Engel, E. Joetzjer, and J. Chave. 2015. Drought tolerance as predicted by leaf water potential at turgor loss point varies strongly across species within an Amazonian forest. Functional Ecology 13:1-4.

Maréchaux, I., M. K. Bartlett, A. Iribar, L. Sack, and J. Chave. 2017. Stronger seasonal adjustment in leaf turgor loss point in lianas than trees in an Amazonian forest. Biology Letters 13:1-4.

Meinzer, F. C., J. L. Andrade, G. Goldstein, N. M. Holbrook, J. Cavelier, and S. J. Wright. 1999. Partitioning of soil water among canopy trees in a seasonally dry tropical forest. Oecolgia 121:293-301.

O'Brien, M. J., et al. 2017. A synthesis of tree functional traits related to drought-induced mortality in forests across climatic zones. Journal of Applied Ecology 54:1669-1686.

Phillips, O. L. 2009. Drought sensitivity of the Amazon rainforest. Science 323:1344-1347.
Phillips, O. L., et al. 2002. Increasing dominance of large lianas in Amazonian forests. Nature 418:770-774.

Pinheiro, J., D. Bates, S. DebRoy, D. Sarkar, and R Core Team. 2019. nlme: linear and nonlinear mixed effects models. $\mathrm{R}$ package version 3.1-140. https://CRAN.R-project.org/packa ge $=$ nlme

Powers, J. S., et al. 2009. Decomposition in tropical forests: a pan-tropical study of the effects of litter type, litter placement and mesofaunal exclusion across a precipitation gradient. Journal of Ecology 97:801-811.

Reich, P. B. 2014. The world-wide 'fast-slow' plant economics spectrum: a traits manifesto. Journal of Ecology 102:275301.

Restom, T. G., and D. C. Nepstad. 2004. Seedling growth dynamics of a deeply rooting liana in a secondary forest in eastern Amazonia. Forest Ecology and Management 190:109-118

Russell, V. L. 2016. Least-squares means: The R package ismeans. Journal of Statistical Software 69:1-33.

Sack, L., P. D. Cowan, N. Jaikumar, and N. M. Holbrook. 2003. The 'hydrology' of leaves: co- ordination of structure and function in temperate woody species. Plant, Cell \& Environment 26:1343-1356.

Schnitzer, S. A. 2005. A mechanistic explanation for global patterns of liana abundance and distribution. American Naturalist 166:262-276.

Schnitzer, S. A. 2015. The contribution of lianas to forest ecology, diversity, and dynamics. Pages 149-160 in N. Parthasarathy, editor. Biodiversity of lianas. Springer International Publishing, Cham, Switzerland.

Schnitzer, S. A. 2018. Testing ecological theory with lianas. New Phytologist 220:366-380.

Schnitzer, S. A., and F. Bongers. 2002. The ecology of lianas and their role in forests. Trends in Ecology \& Evolution 17:223-230.

Schnitzer, S. A., and F. Bongers. 2011. Increasing liana abundance and biomass in tropical forests: emerging patterns and putative mechanisms. Ecology Letters 14:397-406.

Schnitzer, S. A., and G. M. F. van der Heijden. 2019. Lianas have a seasonal growth advantage over co-occurring trees. Ecology 100:e02655.

Schnitzer, S. A., et al. 2012. Liana abundance, diversity, and distribution on Barro Colorado Island, Panama. PLoS ONE 7:e52114.

Schnitzer, S. A., G. M. F. van der Heijden, J. Mascaro, and W. P. Carson. 2014. Lianas in gaps reduce carbon accumulation in a tropical forest. Ecology 95:3008-3017.

Swaine, M. D., and J. Grace. 2007. Lianas may be favoured by low rainfall: evidence from Ghana. Plant Ecology 192:271276.

Tyree, M. T., and H. T. Hammel. 1972. The measurement of the turgor pressure and the water relations of plants by the pressure-bomb technique. Journal of Experimental Botany 23:267-282.

van der Heijden, G. M. F., and O. L. Phillips. 2009. Liana infestation impacts tree growth in a lowland tropical moist forest. Biogeosciences 6:2217-2226.

van der Heijden, G. M., S. A. Schnitzer, J. S. Powers, and O. L. Phillips. 2013. Liana impacts on carbon cycling, storage and sequestration in tropical forests. Biotropica 45:682692.

van der Sande, M. T., L. Poorter, S. A. Schnitzer, B. M. J. Engelbrecht, and L. Markesteijn. 2019. The hydraulic efficiencysafety trade-off differs between lianas and trees. Ecology 100: e02666.

Werden, L. K., B. G. Waring, C. M. Smith-Martin, and J. S. Powers. 2017. Tropical dry forest trees and lianas differ in leaf 
economic spectrum traits but have overlapping water-use strategies. Tree Physiology 38:517-530.

Wishnie, M. H., D. H. Dent, E. Mariscal, J. Deago, N Cedeño, D. Ibarra, R. Condit, and P. M. S. Ashton. 2007. Initial performance and reforestation potential of 24 tropical tree species planted across a precipitation gradient in the Republic of Panama. Forest Ecology and Management 243:39-49.

Wright, S. J., O. Calderon, A. Hernandez, and S. Paton. 2004. Are lianas increasing in importance in tropical forests? A 17-year record from Panama. Ecology 85:484 489.
Wyka, T. P., J. Oleksyn, P. Karolewski, and S. A. Schnitzer. 2013. Phenotypic correlates of the lianescent growth form: a review. Annals of Botany 112:1667-1681.

Yorke, S. R., S. A. Schnitzer, J. Mascaro, S. G. Letcher, and W. P. Carson. 2013. Increasing liana abundance and basal area in a tropical forest: the contribution of long-distance clonal colonization. Biotropica 45:317-324.

Zhu, S.-D., and K.-F. Cao. 2009. Hydraulic properties and photosynthetic rates in co- occurring lianas and trees in a seasonal tropical rainforest in southwestern China. Plant Ecology 204:295-304.

\section{SUPPORTING INFORMATION}

Additional supporting information may be found in the online version of this article at http://onlinelibrary.wiley.com/doi/ 10.1002/ecy.2827/suppinfo

\section{Data Availability}

Data are available from the Dryad Digital Repository: https://doi.org/10.5061/dryad.844rs7d 